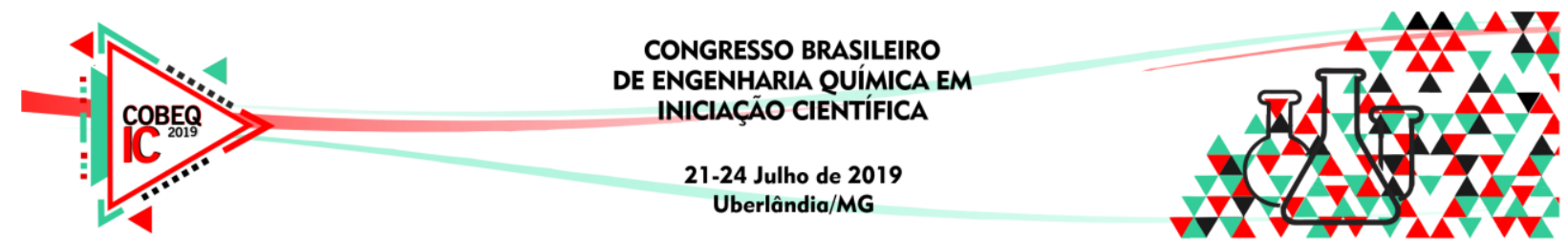

\title{
ESTUDO COMPARATIVO DE COMPÓSITOS PRODUZIDOS A PARTIR DE REJEITOS INDUSTRIAIS DE COBRE E LAMA VERMELHA
}

\author{
I. F. G. CASTRO ${ }^{1}$, D. C. P. CRUZ 1 , J. E. A. $\operatorname{SANTOS}^{1}$, A. J. G. SANTOS ${ }^{2}$, J. A. S. SOUZA ${ }^{3}$ \\ ${ }^{1}$ Universidade Federal do Pará, Faculdade de Engenharia Química, Belém \\ ${ }^{2}$ Campus Universitário de Ananindeua, UFPA, Ananindeua \\ ${ }^{3}$ Programa de Pós-graduação em Engenharia de Recursos Naturais da Amazônia- \\ PRODERNA-UFPA, Belém \\ E-mail para contato: ianfelipe003@gmail.com
}

\begin{abstract}
RESUMO - Os avanços nos estudos de novos materiais proporcionam uma maior diversidade quando se trata de soluções de sustentabilidade já que há uma grande diversidade de recursos renováveis, principalmente na região amazônica. O desenvolvimento desse trabalho propõe analisar compósitos produzidos a partir de rejeitos de Cobre e de lama vermelha, em diferentes proporções, a fim de obter um estudo comparativo entre os mesmos e mostrar os que obtiveram melhores resultados nos testes empregados principalmente de resistência à tração. Dentro das análises os compósitos que melhor obtiveram resistência à tração foi produzido através do resíduo de Cobre com uma proporção de $40 \%$ em relação a matriz polimérica.
\end{abstract}

\section{INTRODUÇÃO}

No âmbito da sociedade atual, dentro dos processos industriais e na área da construção civil faz-se necessária a busca por novos e inovadores tipos de materiais, os quais obtenham os mesmos, ou melhores, resultados diante dos já existentes nos dias de hoje. Essa busca abre portas para diferentes tipos de materiais, dentre eles os compósitos que segundo Borges (2017) tem sido utilizados como alternativa para solucionar o problema com o acumulo de rejeitos industriais indesejados, pois tais materiais são reaproveitados e usados para desenvolver componente em novas tecnologias que gerem materiais de interesse na sociedade. Os compósitos são materiais compostos por duas ou mais fases de diferentes propriedades químicas e físicas, onde a mesma possui uma fase conhecida como matriz, que pode ser: cerâmica, metálica ou polimérica, e outra fase conhecida como reforço, podendo ser de: fibra, partículas ou folhas.

O uso crescente de materiais compósitos em vários domínios tecnológicos modernos despertou atenção considerável nas pesquisas de materiais reforçados e processos avançados de produção. Durante muito tempo esta tecnologia ficou restrita, mas atualmente ela vem sendo aplicada principalmente nas indústrias automotivas, esportivas e de construção civil, pois esses são materiais que apresentam baixo peso (leveza) e um desempenho, principalmente mecânico, superior aos materiais convencionais (TORRES, 2013). 


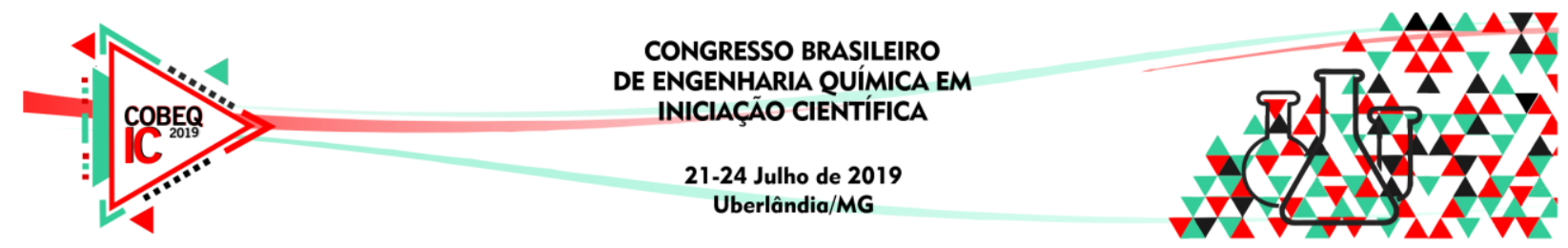

Neste trabalho utilizou-se dois materiais residuais de processos industriais: $\mathrm{O}$ cobre e a lama vermelha, e produziu-se compósitos de matriz polimérica com inserção de rejeito industrial para analisar as propriedades adquiridas. Submeteu-se o material a ensaios mecânicos de tração e posteriormente foram analisadas as características de fratura por meio da microscopia eletrônica de varredura.

\section{MÉTODOS}

\subsection{Preparação E Caracterização Dos Rejeitos Industriais}

Os rejeitos industriais de Cobre e de lama vermelha utilizados foram doados por empresas mineradoras do interior do Pará, sendo o rejeito de Cobre fornecido pela empresa VALE S.A, originário da Mina do Sossego, localizada no município de Canaã dos Carajás e o rejeito de lama vermelha fornecido pela empresa Hydro Alunorte, localizada no município de Barcarena. Para a fabricação desses compósitos, o polímero utilizado foi o poliéster isoftálica (Resina AM 910 AEROJET), de média reatividade, amarelada, não acelerada, com baixa viscosidade. Assim como o agente de cura utilizado na etapa de produção do compósito foi o catalisador, produto comercial BUTANOX M-50 e o acelerador de Cobalto, produto comercial denominado CAT MET UMEDECIDO (Solução de Octoato de Cobalto 1,5\%).

Para executar as etapas de caracterização dos rejeitos e de produção dos compósitos foi necessária uma etapa prévia submetendo os rejeitos de Cobre e lama vermelha à operação de secagem e peneiramento, sendo a primeira realizada em uma estufa (Estufa, de Leo Equipamentos Laboratoriais, T $50{ }^{\circ} \mathrm{C}$ a $250{ }^{\circ} \mathrm{C}$ ) por 24 horas à temperatura de $105{ }^{\circ} \mathrm{C}$. Posteriormente o peneiramento foi realizado manualmente em peneira granulométrica de 100 Mesh da série Tyler. Para realizar a caracterização dos rejeitos industriais foi utilizada a técnica de difratometria de raios-X (DRX), objetivando verificar os minerais presentes em cada amostra. Para a análise foi utilizado um difratômetro de raios-X: D8 Advance da Bruker, com tubo de raios-X. A aquisição dos dados foi realizada com o software X Pert Data collector, versão 3.0, da Panalytical consultando o banco de dados PDF (Power Diffraction File) do ICDD (International Center for Diffraction Data).

\subsection{Produção Dos Compósitos E Propriedade Mecânica}

$\mathrm{Na}$ etapa de produção dos compósitos foi utilizado um molde metálico na forma retangular nas dimensões de $320 \mathrm{~mm}$ x $172,5 \mathrm{~mm}$ x $5 \mathrm{~mm}$. A determinação das massas da resina e dos rejeitos foram feitas previamente utilizando uma balança analítica (Chyo modelo JK 200) onde obteve-se o necessário para cada placa de acordo com a sua porcentagem. A mistura foi colocada no molde e em seguida prensada em prensa hidráulica (Marcon, modelo MPH-15, com capacidade de 15 ton) com carga de 2,5 kN durante o tempo estimado de 20 minutos. Após a etapa de produção das placas, foram realizados os cortes de acordo com a norma ASTM D30395 nas placas. Para cada matriz polimérica com a inserção de rejeito de Cobre e rejeito de lama vermelha produzida nas proporções $10 \%, 20 \%, 30 \%$ e $40 \%$ foram cortados 10 corpos de provas de 2 placas de compósitos produzidas

Para a etapa de ensaio de resistência a tração dos compósitos foi utilizado a máquina universal de tração marca KRATOS 1, modelo IKCL3 com sistema de aquisição de dados, 


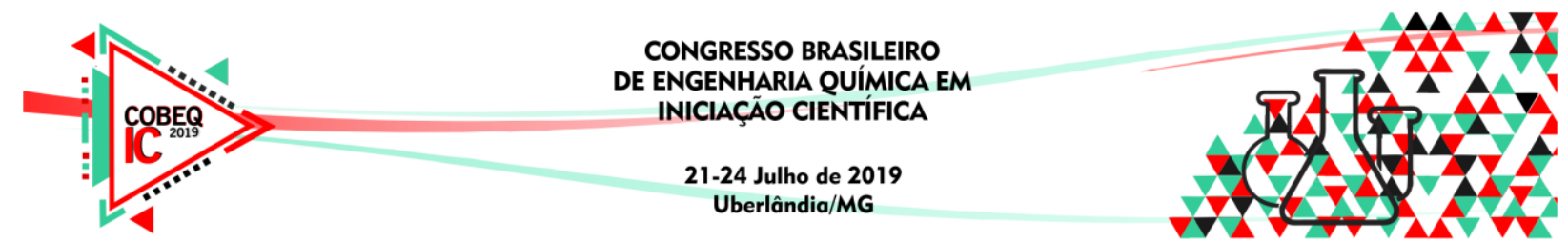

com célula de carga de $5 \mathrm{kN}$, adotando velocidade de $2 \mathrm{~mm} / \mathrm{min}$ e comprimento útil para medição entre garras de $180 \mathrm{~mm}$. Os ensaios de tração foram realizados seguindo a norma ASTM D - 3039 e adotaram as seguintes medidas $250 \mathrm{~mm}$ x $25 \mathrm{~mm}$ x 2,5 mm. O processo de confecção das placas para a produção dos corpos de provas é mostrado abaixo na Figura 1 através do fluxograma.

Figura 1 - Fluxograma das etapas de produção dos compósitos.

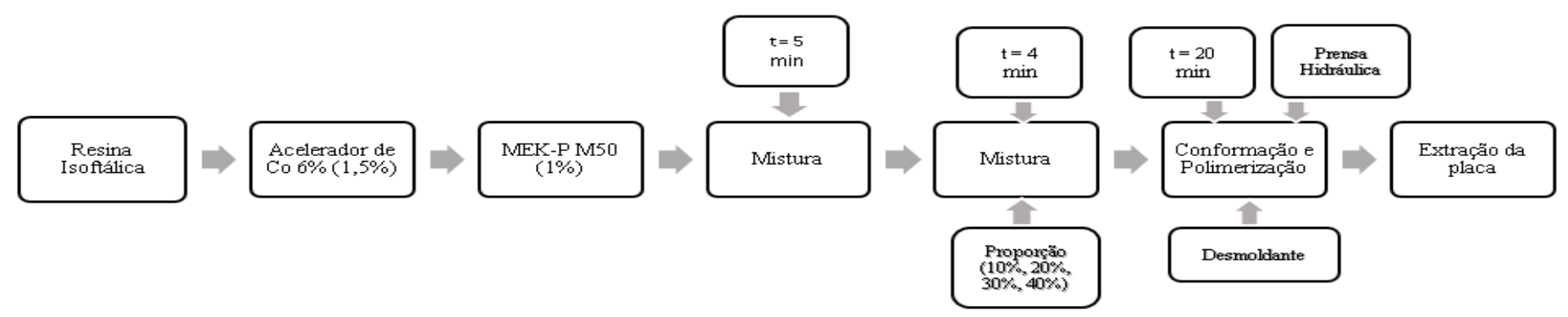

\subsection{Microscopia Eletrônica De Varredura (MEV)}

Após a etapa do ensaio mecânico, as superfícies de fratura dos corpos de prova foram analisadas de forma a observar as alterações morfológicas dos compósitos, por meio do microscópio eletrônico de varredura (MEV) X - Max, sendo que as amostras sofreram um processo de metalização no tempo de 80 segundos.

\section{RESULTADOS E DISCUSSÕES}

\subsection{Caracterização Dos Rejeitos}

A análise de difração de raios-X (DRX) realizada na amostra de rejeito industrial de lama vermelha apresentou, dentre outros componentes, em ordem decrescente de intensidade, a Hematita (H), Sodalita (S), Gibsita (G), Goethita (Gh), e Anatásio (A). Assim como a análise de difração de raios-X (DRX) realizada na amostra de rejeito industrial de Cobre apresentaram como principais componentes mineralógicos em ordem decrescente de intensidade o Quartzo (Q), Albita (A) e Magnetita (M) e o Clinocloro (C). Como mostra a Figura 2

Figura 2 - Difratometria de raios-X da lama vermelha e do Cobre respectivamente

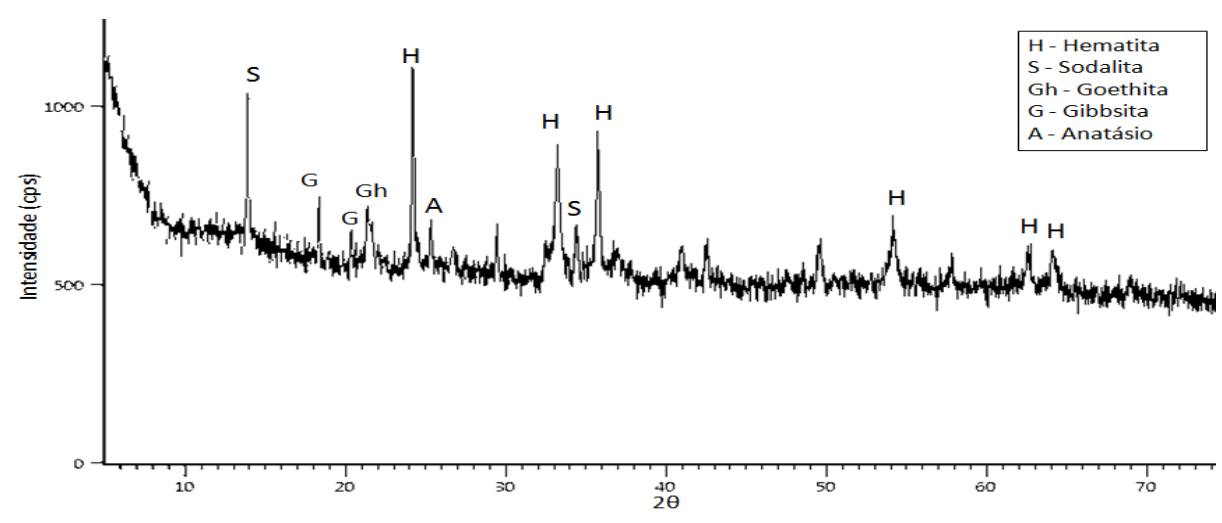



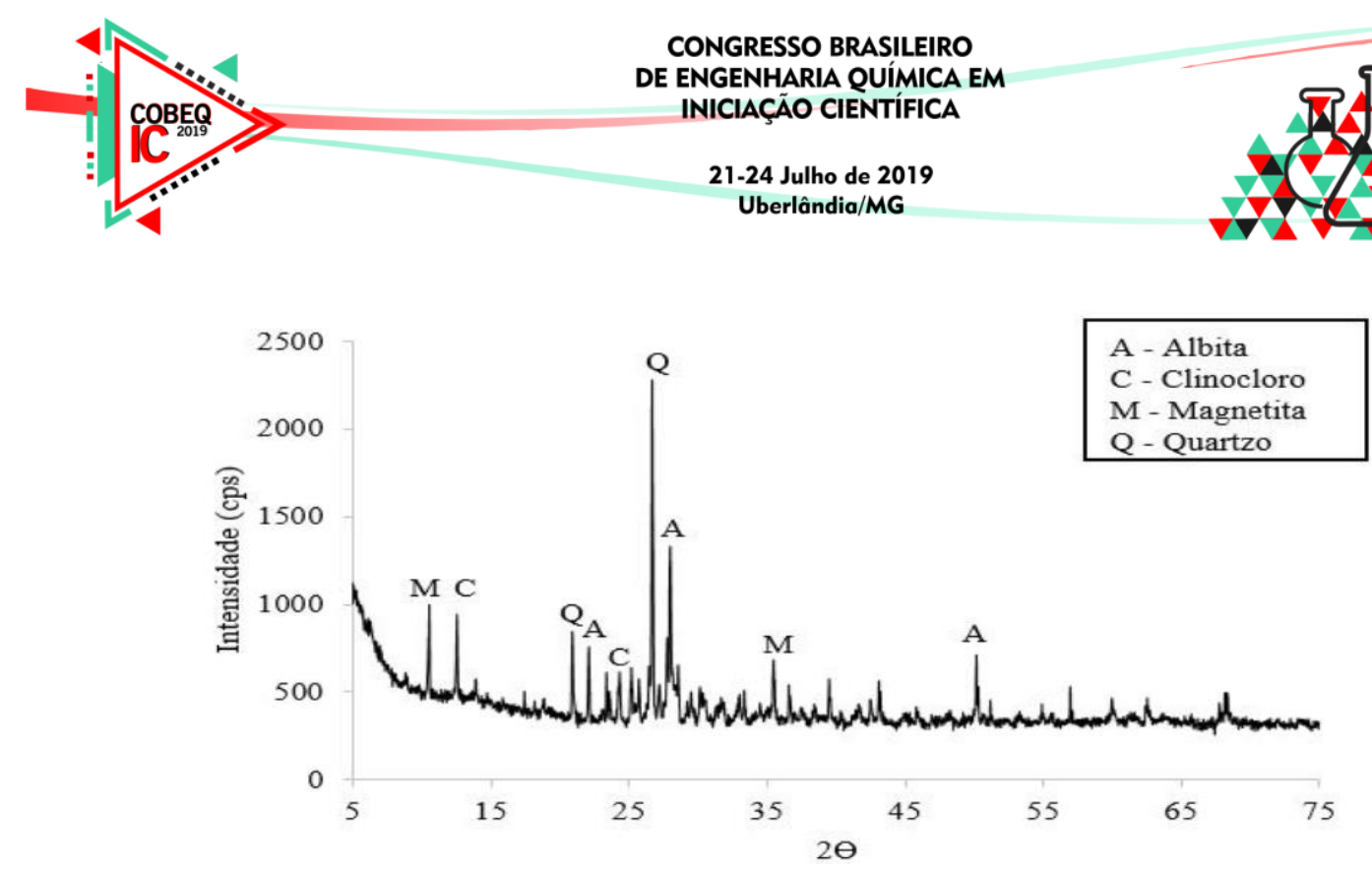

\subsection{Propriedade Mecânica}

Os compósitos poliméricos com inserção de rejeitos industriais foram avaliados quanto a sua resistência mecânica por meio do ensaio de tração, onde foram obtidos os seguintes resultados conforme mostram as Tabelas 1 e 2 .

Tabela 1 - Dados de resistência à tração dos compósitos com inserção de rejeito industrial de Cobre

\begin{tabular}{|c|c|c|c|c|c|}
\hline $\begin{array}{c}\text { Tipo de } \\
\text { amostra }\end{array}$ & $\begin{array}{c}\text { Proporção de } \\
\text { carga }(\%)\end{array}$ & $\begin{array}{c}\text { Tipo Fração } \\
\text { mássica } \\
(\mathrm{FM})(\mathrm{G})\end{array}$ & $\begin{array}{c}\text { Resistência à } \\
\text { tração (MPA) } \\
(\text { Desvio padrão) }\end{array}$ & $\begin{array}{c}\text { Alongamento } \\
(\mathrm{mm})\end{array}$ & $\begin{array}{c}\text { Módulo de } \\
\text { elasticidade } \\
(\mathrm{GPA})\end{array}$ \\
\hline \multirow{2}{*}{$\begin{array}{c}\text { Rejeito } \\
\text { Industrial de } \\
\text { Cobre }\end{array}$} & $\mathrm{RC} 10$ & 31,74 & $25,38( \pm 1,45)$ & 4,63 & 1,04 \\
\cline { 2 - 6 } & $\mathrm{RC} 20$ & 63,48 & $25,18( \pm 1,84)$ & 4,78 & 0,98 \\
\cline { 2 - 6 } & $\mathrm{RC} 30$ & 95,22 & $32,83( \pm 2,81)$ & 5,12 & 1,14 \\
\hline
\end{tabular}

Os ensaios de tração realizados com rejeito industrial de cobre apresentaram um comportamento crescente, sendo que as frações com maiores proporções de rejeitos apresentaram um resultado superior. Segundo Borges (2017) à medida que se aumenta a proporção de rejeito de cobre na matriz, tem-se uma melhor homogeneização e uma melhor compactação, dessa forma pode-se aproveitar melhor a propriedades de ductilidade do cobre por isso que nas frações de 30 e $40 \%$ ela apresenta o comportamento superior.

Tabela 2 - Dados de resistência à tração dos compósitos com inserção de rejeito industrial de lama vermelha

\begin{tabular}{|c|c|c|c|c|c|}
\hline $\begin{array}{c}\text { Tipo de } \\
\text { amostra }\end{array}$ & $\begin{array}{c}\text { Proporção de } \\
\text { carga }(\%)\end{array}$ & $\begin{array}{c}\text { Tipo Fração } \\
\text { mássica } \\
(\text { FM)(G) }\end{array}$ & $\begin{array}{c}\text { Resistência à } \\
\text { tração (MPA) } \\
(\text { Desvio padrão) }\end{array}$ & $\begin{array}{c}\text { Alongamento } \\
(\mathrm{mm})\end{array}$ & $\begin{array}{c}\text { Módulo de } \\
\text { elasticidade } \\
(\mathrm{GPA})\end{array}$ \\
\hline $\begin{array}{c}\text { Rejeito } \\
\text { Industrial de } \\
\text { Lama } \\
\text { Vermelha }\end{array}$ & RVL 10 & 31,74 & $25,89( \pm 7,18)$ & 3,84 & 1,25 \\
\cline { 2 - 6 } & RVL 20 & 63,48 & $32,32( \pm 4,99)$ & 4,61 & 1,33 \\
\cline { 2 - 6 } & RVL 30 & 95,22 & $25,80( \pm 5,35)$ & 4,45 & 1,11 \\
\hline
\end{tabular}




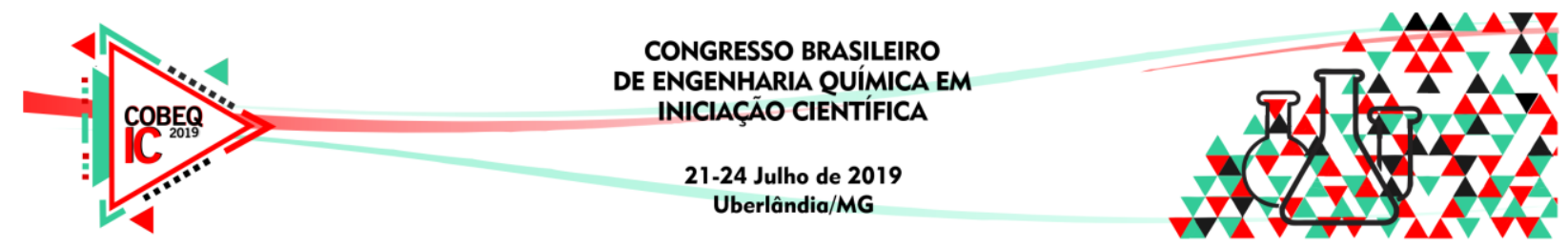

A fração que apresentou resultado superior nos ensaios realizados com rejeito industrial de lama vermelha foi a de $20 \%$ com a resistência a tração de $32,32 \mathrm{MPa}$. Pode-se observar que na análise geral dos dois rejeitos a fração de $10 \%$ do rejeito de cobre apresentou uma resistência menor em relação a de $10 \%$ do compósito feito com lama vermelha. Entretanto para a proporção de $20 \%$ o rejeito de lama vermelha demonstrou um desempenho superior nos testes de resistência a tração. Nas proporções de $30 \%$ e $40 \%$ o rejeito de Cobre se mostrou superior à lama vermelha nos testes.

\subsection{Comparação Dos Resultados}

A comparação dos resultados obtidos pode ser feita graficamente através da Figura 4 onde destacam-se as diferenças no limite de resistência à tração dos rejeitos industriais com o aumento das proporções incorporadas na matriz polimérica. Onde RLV é o rejeito de lama vermelha e RCU é o rejeito de Cobre.

Figura 4 - Limite de resistência à tração dos rejeitos.

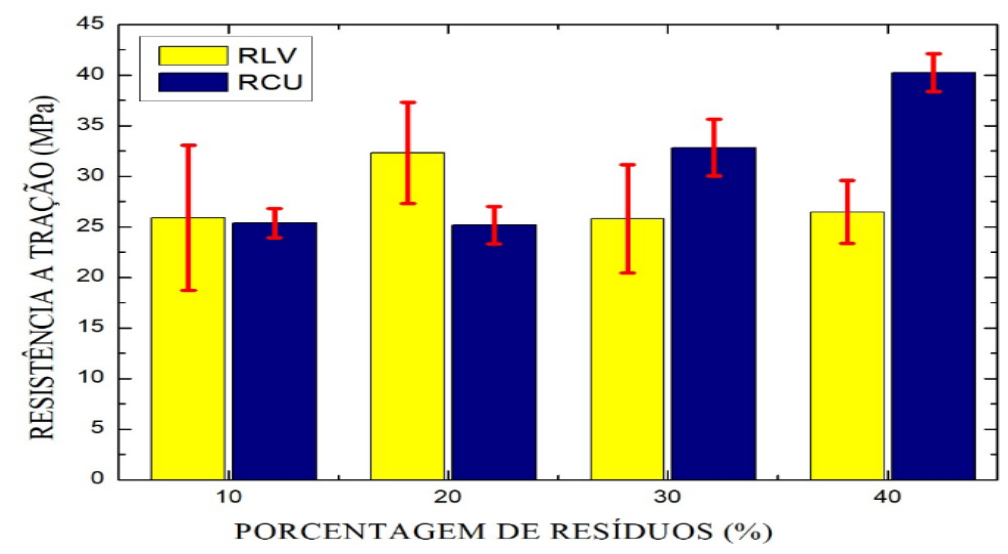

Através da Figura 4 acima não podemos obter uma conclusão evidente determinando qual rejeito fornece maior resistência devido à grande variação dos erros nas medidas das propriedades mecânicas. A única diferença entre as comparações aparece quando se utiliza $40 \%$ do RCU, valor este talvez até inconclusivo devido ao excesso da quantidade de reforço utilizado.

\subsection{Microscopia Eletrônica De Varredura (MEV)}

A Figuras 7 abaixo mostra as superfícies da região onde ocorreram as fraturas nos materiais após a realização dos ensaios de resistência a tração.

As superfícies de fratura do compósito de lama vermelha mostram uma superfície com muitos defeitos (setas azuis em A), o que já não é tão evidente na superfície do compósito de cobre (setas azuis em B). Nota-se ainda uma concentração do resíduo de cobre nas extremidades da matriz (setas laranjas em B), ocasionando uma distribuição irregular do resíduo na matriz. Na Figura 7 (A) percebe-se uma distribuição regular dos resíduos na matriz, não se observa defeitos, de fabricação ou outros tipos. Em (A) também nota-se uma boa aderência matriz e carga, proporcionando melhoras nas propriedades mecânicas. 


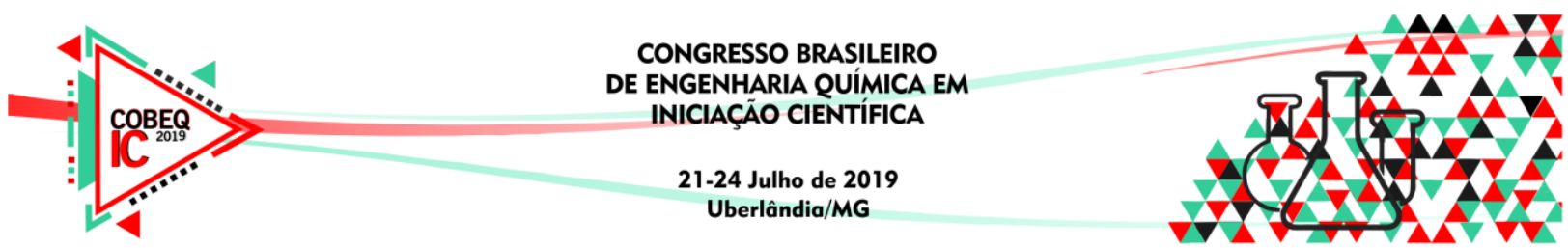

Figura 7. Superfícies com rejeitos de Lama Vermelha (A) e Cobre (B)

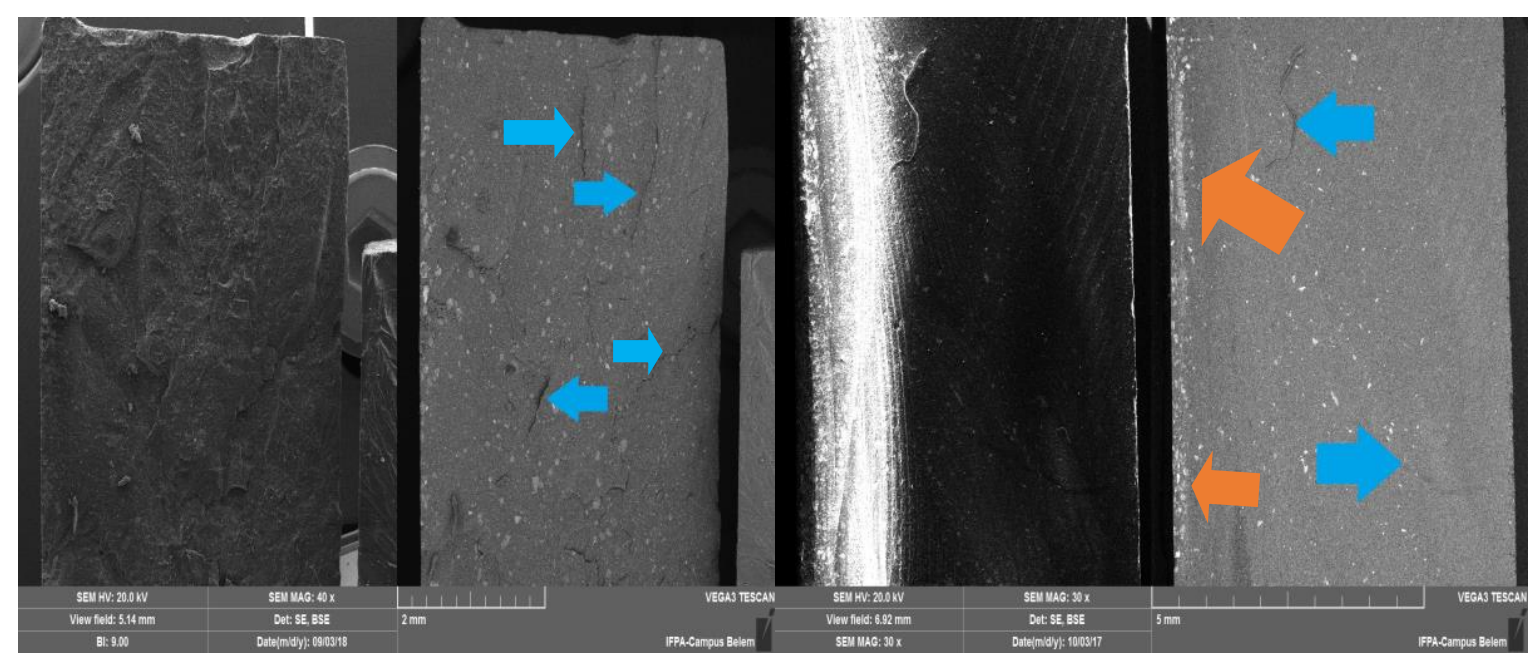

(A)

(B)

\section{CONCLUSÕES}

A fabricação dos compósitos foi feita de maneira coesa com uma boa ancoragem dos rejeitos na matriz polimérica e todos os testes foram realizados de maneira satisfatória.

As análises de DRX mostraram todos os minerais esperados na composição dos materiais estudados nesse trabalho e as imagens geradas pelo MEV revelaram que a região da fratura expõe a distribuição dos rejeitos incorporados na matriz.

O compósito que obteve o maior nível de LRT foi incorporado com rejeito de cobre que atingiu o valor de 40,25 $\mathrm{MPa}$.

\section{REFERÊNCIAS}

BORGES, D. R. Influência do uso de fibras de bambu (Bambusa Vulgaris) tratadas químicamente em compósitos de polímero termofixo carregadas com resíduo da indústria de beneficiamento de minério de cobre. 2018. 102f. Dissertação (Mestrado) - Programa de Pósgraduação em Engenharia Química (PPGEQ), Instituto de Tecnologia, Universidade Federal do Pará, Belém, 2018.

TORRES, R. B. Desenvolvimento de compósito híbrido de fibra de vidro e micropartículas de sílica e cimento para uso em caneleiras. 2013. 70 F. Dissertação (Mestrado em Materiais e Processos de Fabricação) - Universidade Federal de São João Del-Rei, MG, 2013.

CALLISTER, William D., 1940- Ciência e engenharia de materiais: Uma Introdução/ William D. Callister, Jr., David G. Rethwisch; tradução Sergio Murilo Stamile Soares; revisão técnica José Roberto Moraes d' Almeida. - [Reimpr.]. - Rio de Janeiro: LTC, 2013. 